\title{
RADIAL VARIATION IN THE COMPOSITION OF MICRO-INCLUSIONS AND THE CHEMICAL EVOLUTION OF FLUIDS TRAPPED IN DIAMONDS.
}

Oded Navon.

Institute of Earth Sciences, The Hebrew University, Jerusalem 91904, Israel.

Many coated and cubic diamonds from Zaire, Botswana, and other localities carry multitudes of sub-micrometer inclusions that contain $\mathrm{H}_{2} \mathrm{O}-\mathrm{CO}_{2}-\mathrm{SiO}_{2}-\mathrm{K}_{2} \mathrm{O}-\mathrm{rich}$ fluids. The complex internal structure, and the high internal pressure within the

inclusions (Navon, this volume) strongly suggest that the inclusions are primary and that the diamonds grew from the same fluid. If so, the chemical evolution of the trapped fluid may be followed by studying the chemical variation of the micro-inclusions along a radial profile.

More than hundred individual inclusions were analyzed along an approximate radial direction in a diamond from Jwaneng, Botswana. ON-JWN-87 is a 5.6 carat (1121 mg), grey cubic diamond. A $1 \mathrm{~mm}$ thick wafer cut parallel to (100) reveals internal radial zonation. The center of the diamond is free of inclusions. It is surrounded by a $1.8 \mathrm{~mm}$ wide opaque zone where most inclusions are found. The next $0.16 \mathrm{~mm}$ wide zone is inclusion-free, and is followed by a $0.45 \mathrm{~mm}$ wide translucent band with lower density of inclusions. The outer $0.5 \mathrm{~mm}$ is again free of micro-inclusions.

Analyses were performed using a JEOL JXA 8600 electronmicroprobe. A focused, $15 \mathrm{KV}, 50 \mathrm{nA}$ beam scanned a $0.5 \times 0.5 \mu \mathrm{m}$ area (large enough to cover the whole inclusion). Data were collected for 100 seconds using an EDS and four WDS spectrometers, and reduced using a full ZAF correction. Total oxide content varied between 1-33 wt\% (average: 5\%). Compositions were finally normalized to total oxide content of $100 \%$. The $X-Y$ coordination of each analysis spot was recorded and was later projected to calculate the radial position of the microinclusion.

Most analyses yielded an average composition which is broadly similar to that obtained in previous ion-probe analyses (Navon et al., 1989). Twelve inclusions deviate significantly from the average composition. Ten of them have very high oxide content $(12-33 \%)$, and their composition seems to represent discrete mineral phases. Three are rich in CaO, $\mathrm{MgO}$, and $\mathrm{FeO}(>85 \%)$ with $\mathrm{Ca}>\mathrm{Mg}+\mathrm{Fe}$, and $\mathrm{Mg}>\mathrm{Fe}$. They are interpreted as ferroan dolomites. One is rich in Feo and $\mathrm{MgO}$ and is probably a magnesian siderite. Three Si-Fe-Mg-Ca-rich inclusions have an approximate formula of ( $\mathrm{Fe}, \mathrm{Mg}, \mathrm{Ca}) \mathrm{Si}_{2} \mathrm{O}_{5}$ and are probably a mixture of carbonate and quartz, phases that have been previously identified by TEM in the coat of a coated diamond (Guthrie et al., 1989). The composition of two Si-MgFe-K-Al-rich inclusions is close to that of phlogopite. One Si-Ti-rich inclusion was also found.

The composition of all other micro-inclusions was plotted against their radial position (Figure 1 ). $\mathrm{SiO}_{2}$ and $\mathrm{CaO}$ exhibit clear, opposing trends. CaO content increases outward in the internal, inclusion-rich part of the diamond and decreases sharply in outer band. $\mathrm{SiO}_{2}$ decreases in the inner zone, and then increases in the outer zone. Feo, Mgo and to a lesser degree $\mathrm{Na}_{2} \mathrm{O}$ follow the $\mathrm{CaO}$ trend (with $\mathrm{Mg} /(\mathrm{Mg}+\mathrm{Fe})$ almost constant at $0.52+0.05) . \mathrm{TiO}_{2}, \mathrm{Al}_{2} \mathrm{O}_{3}$, and to a lesser extent $\mathrm{K}_{2} \mathrm{O}$ follow the trend of $\mathrm{SiO}_{2}$. The trends are 
better defined in the outer band. The distinction between the two groups of elements was also recognized in a cursory profile done in another diamond.

The chemical evolution of the fluid may be the result of melting, crystallization, or phase separation in a system that may include silicic, carbonatitic, and hydrous fluids. I believe that the complex growth history of micro-inclusionbearing diamonds, the extreme enrichment in incompatible elements, the low Mg/Fe ratio of the fluid, and, as shown below, the chemical evolution of the trapped fluid can be best explained by fractional crystallization of melt at depth. If so, the nature of the crystallizing phases may be deduced from the compositional evolution of the trapped fluid, as recorded in the micro-inclusions.

The increase in $\mathrm{CaO}$ and decrease in $\mathrm{SiO}_{2}$ content in the inner zone suggest the crystallization of a $\mathrm{Ca}$ poor silicic phase. Extrapolation of the linear regression fits of Figure 1 to $\mathrm{CaO}=0$ yields the following approximate composition for the crystallizing phase(s): $\mathrm{SiO}_{2}, 50 \% ; \mathrm{TiO}_{2}, 10 \% ; \mathrm{K}_{2} \mathrm{O}, 10 \%$; $\mathrm{Al}_{2} \mathrm{O}_{3}, 10 \% ; \mathrm{MgO}, 9 \% ; \mathrm{FeO}, 6 \% ;$ and no $\mathrm{Na}_{2} \mathrm{O}$. This composition is broadly similar to that of phlogopite, except for the low Mgo content. It is suggested that removal of phlogopite, coupled with dissolution of a Mgo-rich phase controlled the evolution of the fluid during the stage in which the inner, inciusionrich zone grew.

The chemistry of the outer zone calls for the crystallization of a CaO-rich, silica poor phase. Similar extrapolation to $\mathrm{SiO}_{2}=0$ suggests the removal of a phase(s) with the following composition: $\mathrm{CaO}, 38 \% ; \mathrm{FeO}, 21 \%$; $\mathrm{MgO}, 15 \%$; $\mathrm{K} 2 \mathrm{O}, 15 \%$; and small quantities of $\mathrm{TiO}_{2}, \mathrm{Al}_{2} \mathrm{O}_{3}$, and $\mathrm{Na}_{2} \mathrm{O}(<3 \%)$. Except for the high $\mathrm{K}_{2} \mathrm{O}$, the composition is that of a ferroan dolomite, with Ca:Mg:Fe equals 100:56:44. At present, I can offer no explanation for the almost constant $\mathrm{K}_{2} \mathrm{O}$ concentration along the profile.

It is suggested that the fluid trapped in the microinclusions during the growth of the diamond represents a water-carbonate-rich melt. This melt cooled and evolved under pressures and temperatures of the diamond stability field in the upper mantle. The primary melt was rich in incompatible elements and was probably similar to kimberlites and lamproites. In the final stages, the residual melt was extremely enriched in water, carbonate and incompatible elements, and acquired a very low Mg/Fe ratio. Diamond precipitation commenced during these late stages. It was then accompanied by phlogopite, and later by carbonates. In a few rare cases, these solid phases were also included in the growing diamond. As shown in Figure 2, there exists a good correlation between the chemical trends revealed by the fluid and the composition of the solid trapped phases.

CaO, Mgo and Feo make about $45 \%$ of the total weight of oxides in the inclusions. This, and the high concentration of carbonate detected by IR suggest that the residual fluid was carbonatitic in nature, and that at high pressure, carbonatitic fluids with high content of water and $\mathrm{K}_{2} \mathrm{O}$ may dissolve appreciable quantities of silica (cf. Baker and Wyllie, 1990). The coexistence of carbonate and diamond buffers the oxygen fugacity close to the QFM buffer (Blundy et al., 1991) suggesting that micro-inclusion-bearing diamonds were formed under relatively oxidizing conditions. 
Acknowledgements. I thank J.W. Harris and DeBeers for the diamond, D. Szafranek for EPMA, and N. Summer for review.

Baker, M.B., and Wyllie, P.J. (1990) Liquid immiscibility in a nepheline-carbonate system at 25 kbar. Nature, $346,168-170$.

Blundy, J.D., Brodholt, J.P., Wood, B.J. (1991) Carbon fluid equilibria and the oxidation state of the mantle. Nature, 349, 321-324.

Guthrie, G.D., Navon, O., Veblen, D.R., (1989) Analytical and transmission electron microscopy of turbid coated diamonds (abst). EOS, 70, 510.

Navon, O., Spettel, B., Hutcheon, I.H., Rossman, G.R., Wasserburg, G.J. (1989) Micro-inclusions in diamond from Zaire and Botswana. Extended Abstracts, Workshop on Diamonds, 28 International Geological Congress, July 15-16, Washington, DC.
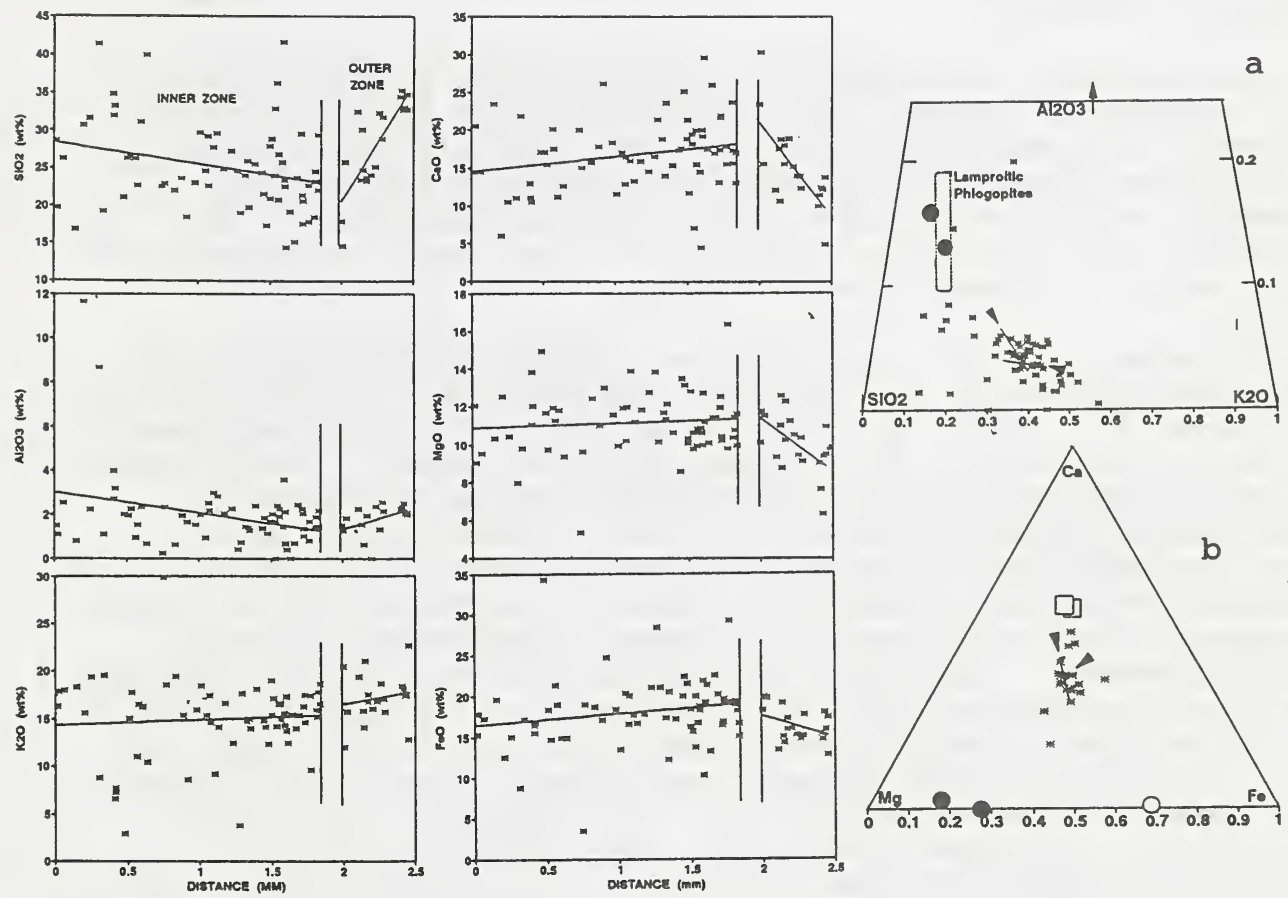

Figure 1. Normalized oxide concentrations vs. radial distance (measured from the boundary between the central zone and the inclusion-bearing inner zone). Lines - Linear regressions of the data in each zone.

Figure 2. a. $\mathrm{Al}_{2} \mathrm{O}_{3}-\mathrm{SiO}_{2}-\mathrm{K}_{2} \mathrm{O}$ of inclusions in the inner zone (horizontal scale expended). Diagonal line $-\mathrm{Al}_{2} \mathrm{O}_{3}-\mathrm{SiO}_{2}-\mathrm{K}_{2} \mathrm{O}$ along the regression line of $\mathrm{Fig}$. 1.; the direction of compositional evolution with time/radius is indicated by the arrow. Sub-horizontal line - the trend in the outer zone. Solid circles: phlogopitic micro-inclusions in the diamond. Rectangle: phlogopites in Western Australian lamproites (Jaques et al., 1986). b. Ca-Mg-Fe molar proportions in outer zone inclusions (asterics and vertical line and arrow). The right arrow indicates the location and direction of the line representing the trend in the inner zone. Composition and direction of the outer zone inclusions may be produced by dolomite removal. Squares-dolomitic inclusions, open circlesideritic inclusion, filled circles-phlogopitic inclusions. 